\title{
Fabricação e caracterização de células fotovoltaicas de silício
}

\section{Gabriel de Loyola Bertão*, Hugo da Silva Alvarez e José Alexandre Diniz}

\section{Resumo}

Este trabalho tem como objetivo a fabricação e caracterização de células solares de heterojunção p-a-Si/n-c-Si de homojunção n-c-Si/p-c-Si/p+-c-S, bem como a execução de processos de otimização de eficiência.

\section{Palavras-chave:}

Célula fotovoltaica, silício amorfo, silício cristalino

\section{Introdução}

A demanda por energia a partir de matrizes não fósseis gera um cenário favorável para o avanço de tecnologias de menor impacto ambiental. Diante disso, este projeto visa o desenvolvimento e a caracterização de células fotovoltaicas e a otimização de sua eficiência.

Foram fabricadas células, de homojunção de silício cristalino (c-Si) e de heterojunção de um filme silício amorfo (a-Si) depositado sobre uma lâmina de cSi. A célula de heterojunção foi produzida a partir da deposição por ECR-CVD de silício amorfo hidrogenado (a-Si:H) sobre uma lâmina de silício tipo $n$ de orientação $<100\rangle$. A face frontal, onde o a-Si:H foi depositado foi submetida ao processo de implantação de íons boro $\left(\mathrm{B}^{+}\right)$ para criação de uma camada dopada tipo $p$ e ao processo de RTP para ativação. Em seguida, litografia para deposição dos contatos de alumínio (Al) por sputtering, revelados por lift-off, e deposição de uma camada antirrefletora (ARC) de nitreto de silício $\left(\mathrm{SiN}_{\mathrm{x}}\right)$ (Etapa I). Após a fabricação, a célula foi submetida a corrosão traseira por ICP para diminuição da espessura da camada n por 10 (Etapa II) e 40 minutos (Etapa III). A célula de homojunção foi produzida a partir da difusão de fósforo, para criação da camada tipo n na face frontal de uma lâmina de silício tipo p com orientação $\langle 100\rangle$, seguida difusão de alumínio depositado por sputtering na face traseira para criação de uma camada p+. Após a difusão, a lâmina passou pela gravação de contatos da mesma forma que fora realizado na célula de a-Si (Etapa I). Por fim, a célula passou por recozimento térmico na presença de $\mathrm{N}_{2}$ e $\mathrm{H}_{2}$ por 1 e 4 minutos (Etapa II e III).

Após a fabricação das células, foi realizada a caracterização J xV com o simulador solar AM 1.5. Assim foi possível a extração de parâmetros como a eficiência

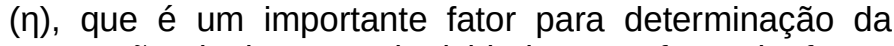
conversão da luz em eletricidade, e o fator de forma (FF), que corresponde a proximidade da conversão com o limite teórico ${ }^{1}$. Sendo $V_{\max }$ e $\mathrm{J}_{\max }$ os valores de tensão e densidade de corrente no ponto de máxima potência, $V_{o c}$ de circuito aberto, $J_{\mathrm{sc}}$ de curto circuito e $\mathrm{P}_{\text {in }}$ de potência incidente.

$$
\eta=\frac{V_{\max } \cdot J_{\max }}{P_{\text {in }}} \quad F F=\frac{V_{\max } \cdot J_{\max }}{V_{o c} \cdot J_{s c}}
$$

\section{Resultados e Discussão}

A queda da eficiência na Etapa III da célula de aSi pode ser associada à ocorrência de corrosão no filme de silício amorfo frontal devido ao tempo prolongado de exposição ao plasma. A queda da eficiência na célula de c-Si na Etapa III ocorreu devido ao prolongamento do recozimento térmico, indicando que o ponto ótimo é próximo a 1 minuto.

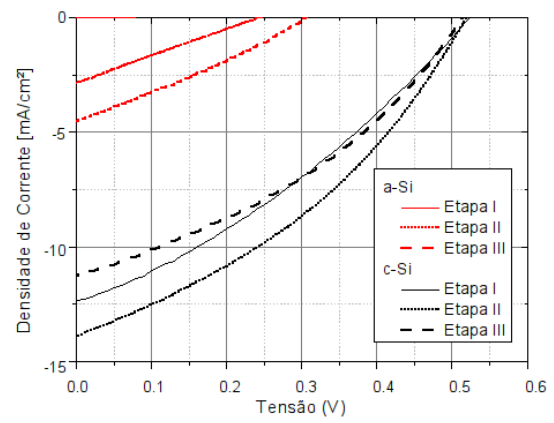

Figura 1. Curva característica das céulas de a-Si e c-Si.

Tabela 1. Parâmetros extraídos das células fotovoltaicas

\begin{tabular}{|c|c|c|c|c|c|c|}
\cline { 2 - 7 } \multicolumn{1}{c|}{} & \multicolumn{3}{c|}{ Célula de a-Si } & \multicolumn{3}{c|}{ Célula de c-Si } \\
\cline { 2 - 7 } \multicolumn{1}{c|}{} & $\mathrm{I}$ & $\mathrm{II}$ & III & I & II & III \\
\hline Vmax [mV] & 8,76 & 159 & 166 & 300 & 310 & 320 \\
\hline Jmax [mA/cm²] & 0,03 & 2.5 & 2.0 & 7.0 & 9.1 & 6.6 \\
\hline Voc [mV] & 170 & 323 & 328 & 520 & 520 & 510 \\
\hline Jsc [mA/cm²] & 0.33 & 4.6 & 3,91 & 12.3 & 14.97 & 11.26 \\
\hline$\eta[\%]$ & $<0,001$ & 0,4 & 0,34 & 2.1 & 2.6 & 2.1 \\
\hline FF [\%] & 0,04 & 27,1 & 26,2 & 32.6 & 36.04 & 36.79 \\
\hline
\end{tabular}

\section{Conclusão}

Embora as células não apresentem alta eficiência como as presentes no mercado (na ordem de dezenas ${ }^{1}$ ) é necessário salientar que os processos de corrosão e recozimento ocasionaram um aumento de eficiência de cerca de quatro ordens de grandeza e $23.8 \%$, respectivamente. Um próximo trabalho poderia explorar os canais criados durante a corrosão da célula de a-Si para a circulação de um fluido refrigerante que diminua a perda de eficiência associada ao aumento de temperatura e a deposição de uma camada antirrefletora na face frontal da célula de c-Si.

\section{Agradecimentos}

Ao CNPq pelo financiamento, ao Hugo S. Alvarez pela fabricação das células e ao CCSNano pelo apoio.

${ }^{1}$ SMETS, A et al. Solar energy: The Physics and Engineering of Photovoltaic Conversion, Technologies and Systems. [S.1]: UIT Cambridge, 2016. ISBN 9781906860325. 